\title{
Statistical Evaluation of Models for the Removal of Heavy Metals in Adsorption Columns Using Bio-Waste Materials
}

\author{
P. Musonge \\ Institute of Systems Science, Durban University of Technology, Durban, South Africa.
}

ORCID: 0000-0001-9049-8655

\begin{abstract}
Agro-based waste constitutes a significant amount of waste in major urban and rural communities and is therefore part of any municipal waste management strategy. The feasibility of the use of agro-based waste as adsorbents for heavy metals has been studied by a number of researchers. However, there is no comprehensive study dealing with the selection of models for design. The key variables in the process are; the heavy metals concentration, the mass of bio-sorbent and the flow rate of the influent waste water. Several models that were not originally derived for the adsorption of heavy metals are used to predict the breakthrough curves. In this study a statistical analysis of the performance of two of the widely used models (YoonNelson and Thomas) was carried out in order to propose a suitable model for use in design, while pointing out the limitations. The study further investigates the use of mean empirical parameters and fitting the coefficients as a function of process parameters in an attempt to generalize the models for easy application. Both models perform equally well with the model coefficients adjusted with changes in the flow parameters. The use of average values of the parameters to generalize the models shows that the Yoon-Nelson model is incapable of predicting the performance with changes in the flow parameters. Based on available data and the results of the present analysis, the Thomas model is recommended for the design of adsorption columns for heavy metals.
\end{abstract}

Keywords: Bio-sorption columns, breakthrough curves, heavy metals, adsorption models.

\section{INTRODUCTION}

Wastewater contaminated with heavy metals is a global phenomenon due to industrialization. Wastes that contain heavy metals eventually released into the environment resulting in severe health and environmental risks. As a result, there has been a continuous, coordinated and significant moves over the past 2-3 decades in individual countries to regulate the levels of heavy metals present in potable water or industrial wastewater discharged to the environment. According to the WHO [1], even trace amounts of some of the metals can be harmful to humans. Municipal wastewater treatment plants are sometimes unable to guarantee the regulatory levels of these toxic metals in portable water. It has therefore become desirable to introduce technologies that can serve as finishing steps in current water treatment processes to guarantee the safety of portable water. The search for a low cost and easily available adsorbents has led to the investigation of materials of agricultural and biological origin, such as agricultural solid waste, along with industrial by-products (Aksu and Gonen[2]). One of such emerging technologies is the use of biomass as adsorbents because of its low cost and availability. Several studies have demonstrated the ability of biomass (natural and modified), to remove low concentrations of heavy metals in water. The most commonly used adsorbent in wastewater treatment is activated carbon but in spite of its effectiveness, the high cost of activated carbon has limited its use. The focus now is on experimentation in continuous systems, necessary to generate the concentration - time curves (the breakthrough curves), that is essential for design and scale-up. This should provide a way of recycling this waste material by putting it to use.

\section{DYNAMIC ADSORPTION MODELS}

The variation of the concentration profiles of pollutants in water through a fixed bed vary in space and time and therefore require a mathematical and quantitative modelling approach. A number of models have been used to represent the dynamic behaviour of an adsorption column (Fig 1). The study focuses on the use of two dynamic models for the prediction of breakthrough curves using biomass waste.

\subsubsection{Thomas Model}

Thomas [3] developed a model based on a number of assumptions; the physical properties of the solid and liquid phases and the column void fraction are constant, the process follows a Langmuir adsorption isotherm at equilibrium with the assumption of a pseudo second order reaction, negligible axial and radial dispersion in the fixed bed column, and finally negligible intra particle diffusion and external resistance during the mass transfer processes. The model consists of five process variables and two empirical constants. The well-known Thomas model is given by:

$$
\frac{C_{t}}{C_{o}}=\frac{1}{\left[E X P\left[\left(\frac{\mathrm{K}_{\mathrm{TH}} \mathrm{q}_{\mathrm{o}} \mathrm{m}}{\mathrm{Q}}-\mathrm{K}_{\mathrm{TH}} \mathrm{C}_{\mathrm{o}} \mathrm{t}\right)\right]+1\right]}
$$

From equation $1, \mathrm{~K}_{\mathrm{TH}}$ is the Thomas model constant (L/mg.min), $\mathrm{q}_{\mathrm{o}}$ is the adsorption capacity $(\mathrm{mg} / \mathrm{g}), \mathrm{m}$ is the 
adsorbent mass $(\mathrm{g})$ and $\mathrm{Q}$ is the volumetric flow rate $(\mathrm{mL} / \mathrm{min})$, $\mathrm{C}_{\mathrm{t}}$ and $\mathrm{C}_{\mathrm{o}}$ are effluent and influent adsorbate concentrations $(\mathrm{mg} / \mathrm{L})$ respectively.

\subsubsection{Yoon - Nelson Model}

The Yoon-Nelson model [4] assumes that the rate of decrease in the probability of adsorption of adsorbate molecule is proportional to the probability of the adsorbate adsorption and the adsorbate breakthrough on the adsorbent. The model consists of three process variables and two empirical constants. The rough form of the Yoon-Nelson model makes it less valuable or convenient to obtain process variables and to predict adsorption under a variety conditions $\mathrm{Xu}$, Cai and Pan [5]. The Yoon-Nelson model can be expressed as follows;

$$
\frac{C_{t}}{C_{o}}=\frac{E X P\left(K_{Y N} t-K_{Y N} \tau\right)}{\left[1+E X P\left(K_{Y N} t-K_{Y N} \tau\right)\right]}
$$

Where $C_{t}$ and $C_{o}$ are effluent and influent adsorbate concentrations $(\mathrm{mg} / \mathrm{L})$ respectively, $\mathrm{K}_{\mathrm{YN}}$ is the rate constant $\left(\mathrm{min}^{-1}\right), \mathrm{t}$ is the processing time ( $\left.\mathrm{min}\right)$ and $\tau$ is the time required for $50 \%$ adsorbate breakthrough (min).

\subsection{Performance Metrics}

Statistical measures of accuracy are significant in determining the performance of dynamic adsorption models. The widely used error functions to assess the performance are namely; mean absolute error (MAE), root mean squared error (RMSE) and coefficient of determination $\left(\mathrm{R}^{2}\right)$, among others. Mean absolute error is normally used due to its simplicity, however, this function cannot determine the severity of the error and is meaningless in reaching accuracy of the prediction method for multiple data series. The above-mentioned error function is significant in reaching accuracy of the prediction method for a single data array.

$$
\mathrm{MAE}=\frac{1}{n} \sum_{\mathrm{i}=1}^{\mathrm{n}}\left|\frac{\mathrm{C}_{\mathrm{t}}}{\mathrm{C}_{\mathrm{o}}}-\frac{\widehat{\mathrm{C}_{\mathrm{t}}}}{\mathrm{C}_{\mathrm{o}}}\right|_{\mathrm{i}}
$$

In order to eliminate the above-mentioned weakness, RMSE function can be applied. In most optimization cases, RMSE is used since the function incorporates the sizes of faults and is a more precise measure of accuracy.

$$
\operatorname{RMSE} \sqrt{\frac{1}{\mathrm{n}} \sum_{\mathrm{i}=1}^{\mathrm{n}}\left(\frac{\mathrm{C}_{\mathrm{t}}}{\mathrm{C}_{\mathrm{o}}}-\frac{\widehat{\mathrm{C}_{\mathrm{t}}}}{\mathrm{C}_{\mathrm{o}}}\right)_{i}^{2}}
$$

Where $\frac{\mathrm{C}_{\mathrm{t}}}{\mathrm{C}_{\mathrm{o}}}$ and $\frac{\widehat{\mathrm{C}_{\mathrm{t}}}}{\mathrm{C}_{\mathrm{o}}}$ are actual or experimental and predicted or observed nominal concentrations, respectively, and $\mathrm{n}$ is the number of data points or sample size.

For all error types, smaller values are considered favourable (Kardam et al.[6], Kiraz et al.[7]).

\section{EXPERIMENTAL CONDITIONS}

All experiments were conducted in a downward flow dynamic adsorption column as shown in Fig. 1 below.

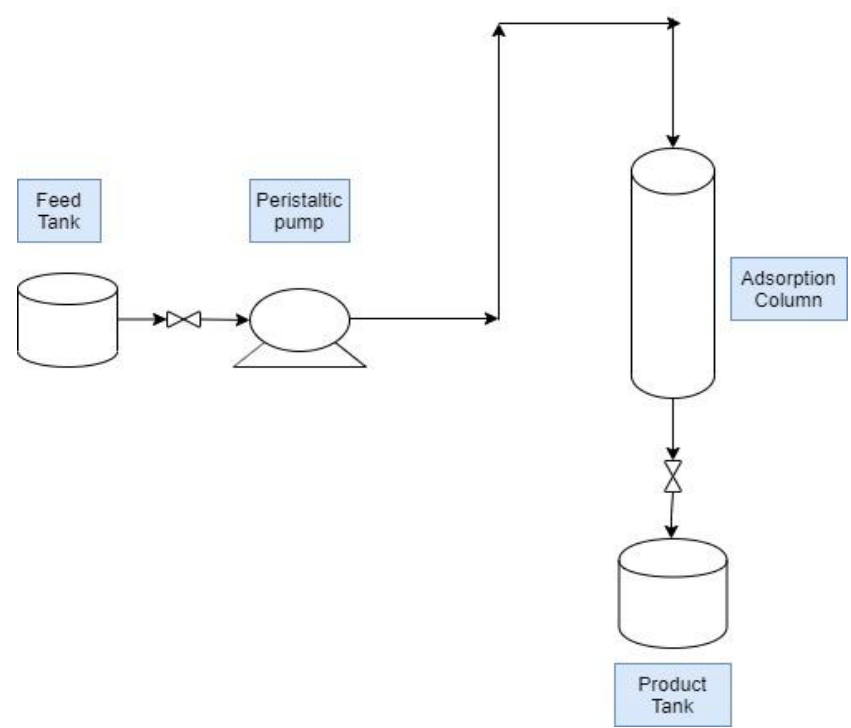

Fig.1: A generalised schematic representation of a lab scale adsorption column.

The experimental conditions for the three case studies [8], [9], [10] are summarized in Table 1, below. The data presented focuses on the height/mass of adsorbents in the column but the flowrate and initial metal concentration of the adsorbates were also varied.

Table 1: Experimental conditions

\begin{tabular}{|c|c|c|c|}
\hline Reference & $\begin{array}{c}{[8]} \\
\text { Experiment 1 }\end{array}$ & $\begin{array}{c}{[9]} \\
\text { Experiment 2 }\end{array}$ & $\begin{array}{c}{[10]} \\
\text { Experiment 3 }\end{array}$ \\
\hline Biosorbent(s) & $\begin{array}{c}\text { Modified } \\
\text { Agaricus } \\
\text { Bisorous }\end{array}$ & $\begin{array}{c}\text { Coconut } \\
\text { Shell }\end{array}$ & $\begin{array}{c}\text { Tea } \\
\text { Watse(TW), } \\
\text { Maple Leaves } \\
\text { and Mandarin } \\
\text { Peel }\end{array}$ \\
\hline Metal & Lead & Copper & Cadmium \\
\hline pH & 5.5 & 7 & 5.5 \\
\hline $\begin{array}{c}\text { Flowrate } \\
\text { (ml/min) }\end{array}$ & 3 & 10 & 10 \\
\hline $\begin{array}{c}\text { Concentration } \\
\text { (mg/L) }\end{array}$ & 50 & 10 & 20 \\
\hline \begin{tabular}{c} 
Bed Depth (cm) \\
\hline
\end{tabular} & $2,4,6$ & $5,10,15,20$ & $9.5,21,31$ \\
\hline
\end{tabular}

\section{MODEL APPLICATIONS}

\subsection{Use of calculated model coefficeints.}

Table 2, shows the calculated empirical coefficients derived from models through linearization with changes in mass 
International Journal of Engineering Research and Technology. ISSN 0974-3154, Volume 13, Number 10 (2020), pp. 2968-2972

(C) International Research Publication House. https://dx.doi.org/10.37624/IJERT/13.10.2020.2968-2972

(height) of adsorbents and also reports the average values within the range of the experimental parameters.

Table 2: Thomas and Yoon Nelson parameters for the three experiments

\begin{tabular}{|c|c|c|c|c|}
\hline Variable & \multicolumn{2}{|c|}{ Thomas parameters } & \multicolumn{2}{|c|}{$\begin{array}{l}\text { Yoon Nelson } \\
\text { Parameters }\end{array}$} \\
\hline \multicolumn{5}{|c|}{ Experiment 1} \\
\hline $\begin{array}{l}\text { Height } \\
\text { (cm) }\end{array}$ & $\begin{array}{c}\mathrm{K}_{\mathrm{TH}}(\mathrm{ml} \cdot \mathrm{mg} \\
\left.{ }^{1} \cdot \mathrm{min}^{-1}\right)\end{array}$ & $\begin{array}{c}\mathrm{q}_{\mathrm{o}} \\
\left(\mathrm{mg} \cdot \mathrm{g}^{-1}\right)\end{array}$ & $\mathrm{K}_{\mathrm{NY}} \min ^{-1}$ & $\mathrm{~T}(\min )$ \\
\hline 2 & 0,000835 & 67,72 & 0,042 & 180,6 \\
\hline 4 & 0,000573 & 63,06 & 0,029 & 336 \\
\hline 6 & 0,000467 & 59,16 & 0,023 & 473,4 \\
\hline Average & 0,000625 & $\begin{array}{c}63,3133 \\
3\end{array}$ & 0,032 & 330 \\
\hline \multicolumn{5}{|c|}{ Experiment 2} \\
\hline \multicolumn{5}{|l|}{ Mass (mg) } \\
\hline 729 & 26,99 & 0,039 & 0,18 & 45,66 \\
\hline 972 & 17,21 & 0,043 & 0,24 & 65,6 \\
\hline Average & 22,1 & 0,0411 & 0,21 & 55,63 \\
\hline \multicolumn{5}{|c|}{ Experiment 3} \\
\hline 5 & 1,77 & 4,25 & 0,038 & 101,6 \\
\hline 10 & 1,125 & 4,08 & 0,016 & 210,7 \\
\hline 15 & 0,985 & 3,92 & 0,029 & 283,2 \\
\hline Average & 1,29 & 4,08 & 0,028 & 198,5 \\
\hline
\end{tabular}

Figs 2-4 show the performance of the two models using the model coefficients, evaluated as a function of changes in mass.

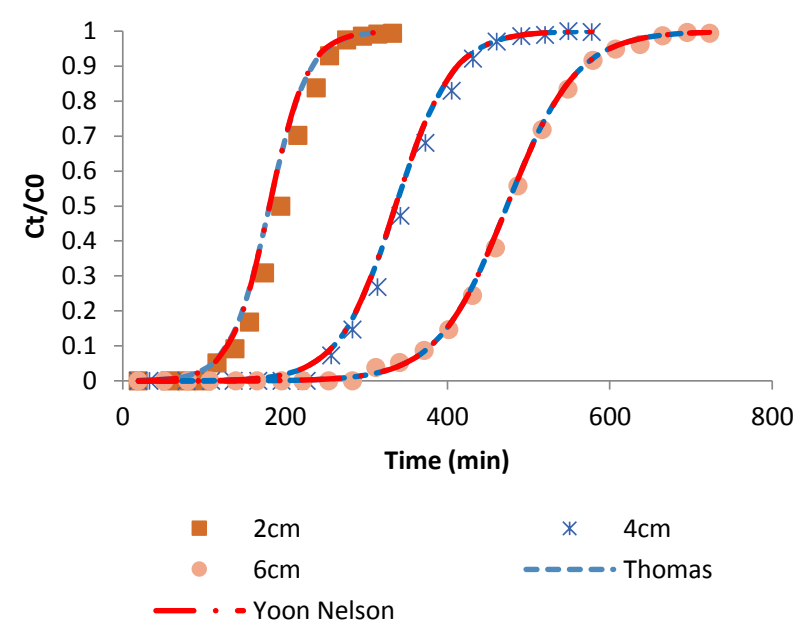

Fig 2: Effect of bed height on breakthrough curves - experiment 1

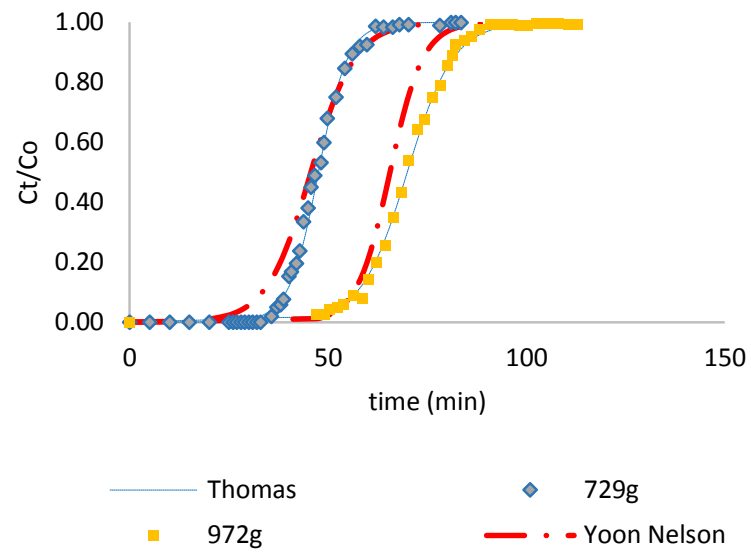

Fig 3: Effect of bed height on breakthrough curves - experiment 2

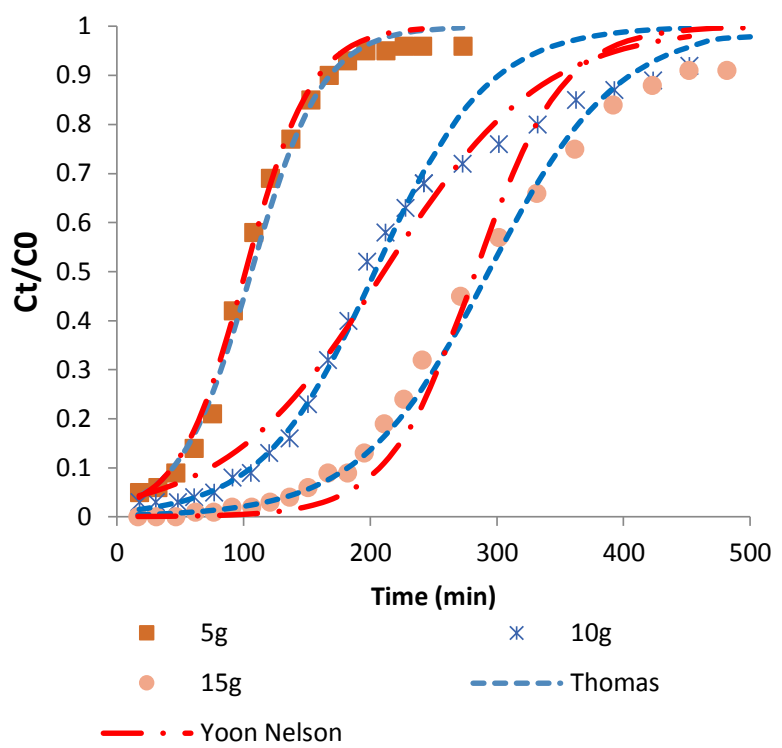

Fig 4: Effect of bed height on breakthrough curves, experiment 3

The statistical metrics obtained for the predictions in Figs 2-4, are shown in Table 3. There is good agreement between experimental and predicted data using all three statistical metrics for both models. RMSE and MAE $<1$ 
Table 3: Experimental and theoretical breakthrough curves regression and error analyses for experiment 1-3

\begin{tabular}{|c|c|c|c|c|c|c|}
\hline \multirow[t]{2}{*}{ Parameters } & \multicolumn{3}{|c|}{ Thomas } & \multicolumn{3}{|c|}{ Yoon-Nelson } \\
\hline & RMSE & MAF & $\mathbf{R}^{2}$ & RMSE & MAE & $\mathbf{R}^{2}$ \\
\hline \multicolumn{7}{|l|}{ Height $(\mathrm{cm})$} \\
\hline \multicolumn{7}{|c|}{ Experiment 1} \\
\hline 2 & 0,07 & 0,05 & 0,9946 & 0,07 & 0,05 & 0,9946 \\
\hline 4 & 0,03 & 0,02 & 0,996 & 0,03 & 0,02 & 0,996 \\
\hline 6 & 0,01 & 0,01 & 0,9923 & 0,01 & 0,009 & 0,9923 \\
\hline \multicolumn{7}{|l|}{$\operatorname{Mass}(\mathrm{g})$} \\
\hline \multicolumn{7}{|c|}{ Experiment 2} \\
\hline 729 & 0,03 & 0,02 & 0,9808 & 0,08 & 0,06 & 0,9808 \\
\hline 972 & 0,01 & 0,01 & 0,952 & 0,11 & 0,07 & 0,952 \\
\hline \multicolumn{7}{|c|}{ Experiment 3} \\
\hline 5 & 0,03 & 0,02 & 0,9376 & 0,03 & 0,02 & 0,9376 \\
\hline 10 & 0,05 & 0,03 & 0,9396 & 0,05 & 0,04 & 0,9396 \\
\hline 15 & 0,03 & 0,02 & 0,9645 & 0,07 & 0,05 & 0,9645 \\
\hline
\end{tabular}

\subsection{Model Generalization}

The empirical coefficients for the Thomas model do not vary significantly with changes in mass, while $\tau_{50}$, varies significantly in the Yoon-Nelson model. Figs. 5-6 show the performance of the two models using the average values of the model coefficients in the Table 1 .

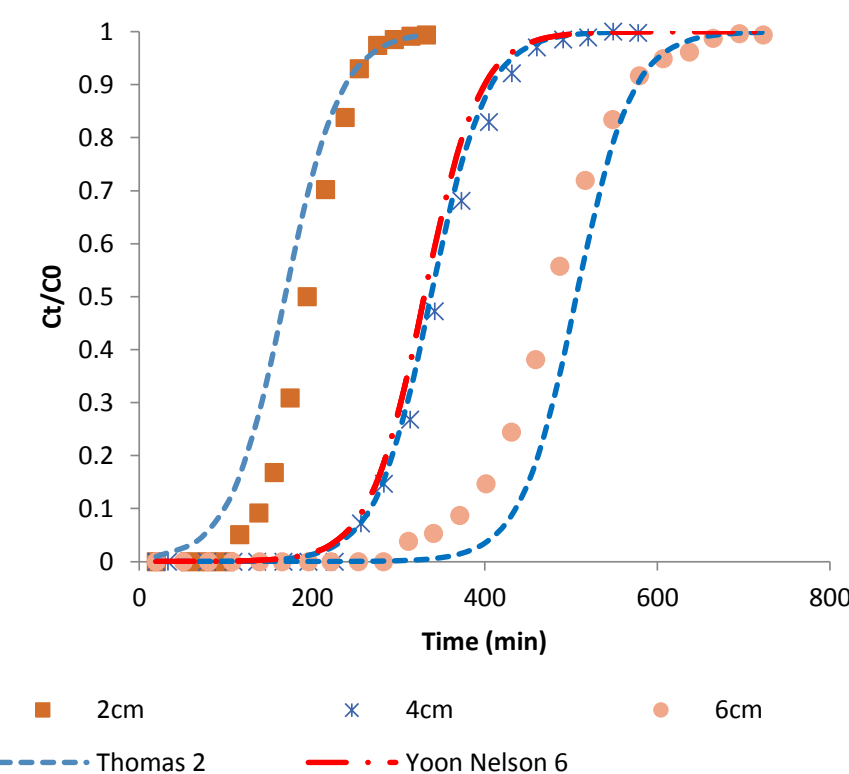

Fig. 5: Effect of bed height on breakthrough curves using average Thomas and Yoon-Nelson parameters, experiment 3 .

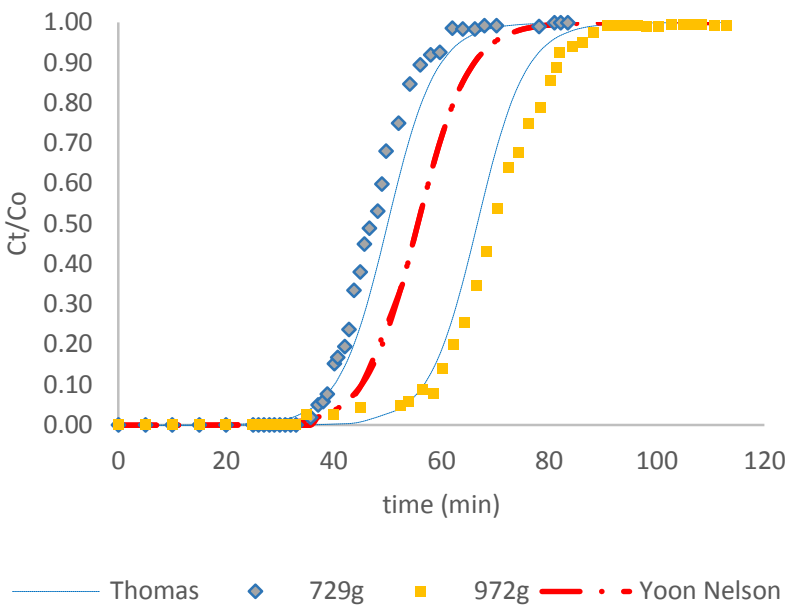

Fig. 6: Effect of bed height on breakthrough curves using average Thomas and Yoon-Nelson parameters, experiment 2

It is clear from Figs 5-6, that using the mean values of the model coefficients does not respond to changes in mass for the YoonNelson model. The statistical metrics in Table 4, shows that using this approach the Thomas model performs better the Yoon-Nelson model.

Table 4: Mean Experimental and theoretical breakthrough curves regression and error analyses for experiment 1-3

\begin{tabular}{|c|c|c|c|c|c|c|}
\hline Parameters & \multicolumn{3}{|c|}{ Thomas } & \multicolumn{3}{|c|}{ Yoon-Nelson } \\
\hline & RMSE & MAE & $\mathbf{R}^{2}$ & RMSE & MAE & $\mathbf{R}^{2}$ \\
\hline Mass(g) & \multicolumn{7}{|c|}{ Experiment 1 } \\
\hline \multicolumn{7}{|c|}{ Experiment 2 } \\
\hline $\mathbf{2}$ & 0,12 & 0,08 & 0,9969 & 0,50 & 0,38 & 0,9969 \\
\hline $\mathbf{4}$ & 0,03 & 0,02 & 0,996 & 0,05 & 0,03 & 0,996 \\
\hline $\mathbf{6}$ & 0,08 & 0,04 & 0,9923 & 0,41 & 0,398 & 0,9923 \\
\hline $\mathbf{7 2 9}$ & 0,08 & 0,06 & 0,961 & 0,22 & 0,16 & 0,961 \\
\hline $\mathbf{9 7 9}$ & 0,07 & 0,05 & 0,967 & 0,29 & 0,207 & 0,982 \\
\hline \multicolumn{7}{|c|}{ Experiment 3 } \\
\hline $\mathbf{5}$ & 0,06 & 0,05 & 0,9376 & 0,40 & 0,33 & 0,9397 \\
\hline $\mathbf{1 0}$ & 0,06 & 0,05 & 0,9667 & 0,07 & 0,04 & 0,9396 \\
\hline $\mathbf{1 5}$ & 0,07 & 0,05 & 0,9645 & 0,24 & 0,177 & 0,9645 \\
\hline
\end{tabular}

The mean values of the Thomas coefficients can be used to generalize the model. Given that the value of $\tau_{50}$ changes significantly with variations in mass for the Yoon-Nelson model, this coefficient was model as function of the mass of the adsorbent. The data was best fitted with a linear relationship as shown in Table 5. The predictions using the average values of the Thomas coefficients and a linear fit of the Yoon-Nelson 
model shown in Fig.7 provide for a way of generalizing the two models.

Table 5: Linearization of $\tau_{50}$

\begin{tabular}{|c|c|c|}
\hline Mass(g) & $\tau(\min )$ & $\begin{array}{l}\text { Calculated } \\
\qquad \tau(\min )\end{array}$ \\
\hline \multicolumn{3}{|c|}{ Experiment 1} \\
\hline \multicolumn{3}{|c|}{$\begin{array}{c}\text { Mass }=0,0027 \tau-0.1003, R^{2}=0,9988 \\
K_{N Y}=0.03153\end{array}$} \\
\hline & $\begin{array}{l}\text { experimental } \\
\text { values }\end{array}$ & linearized values \\
\hline 0,4 & 180,6 & 185,3 \\
\hline 0,8 & 336 & 333,4 \\
\hline 1,2 & 473,5 & 481,6 \\
\hline \multicolumn{3}{|c|}{ Experiment 3} \\
\hline \multicolumn{3}{|c|}{$\begin{array}{c}\text { Mass }=0,0543 \tau-0,7846, R^{2}=9866 \\
K_{\mathrm{NY}}=0.027667\end{array}$} \\
\hline & $\begin{array}{c}\text { experimenta } \\
\text { values }\end{array}$ & $\begin{array}{l}\text { linearized } \\
\text { vales }\end{array}$ \\
\hline 5 & 101,6 & 106,5 \\
\hline 10 & 210,7 & 198,6 \\
\hline 15 & 283,2 & 290,7 \\
\hline
\end{tabular}

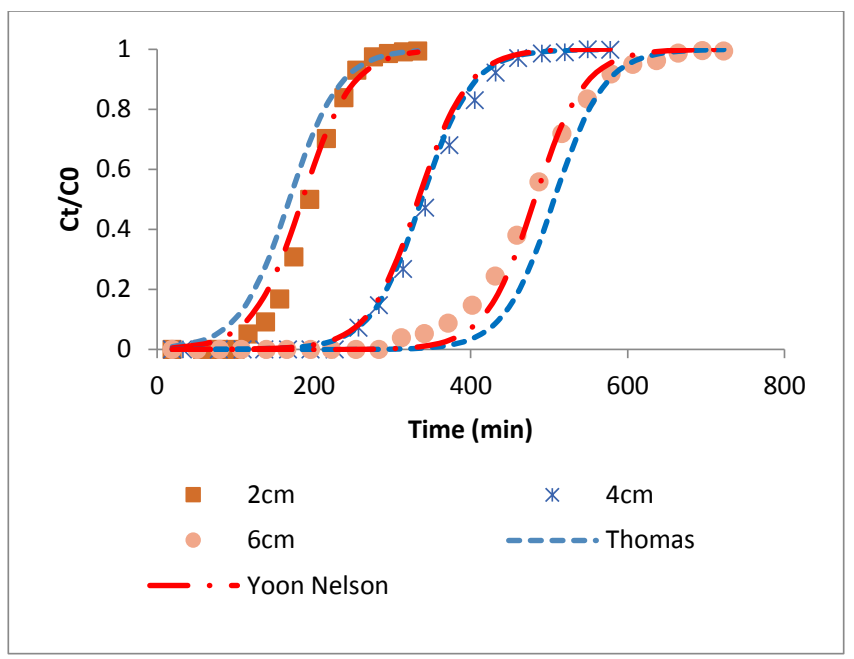

Fig. 7: Effect of bed height on breakthrough curves using average Thomas and linear fitted Yoon-Nelson parameters - experiment 3.

\section{CONCLUSION}

The overall objective of the study was to investigate the possibility of generalizing the models for scale up purposes. Good agreement was found with the experimental data for both models with the empirical coefficients calculated for each set of experimental conditions. This performance is also confirmed from recent studies [11], using other bio-sorbents. To adjust the empirical constants with every change in flow parameters, means new experiments must be carried out making it difficult to scale up and control adsorption columns. The use of the average values of the empirical coefficients differentiates the models. The Thomas model has the ability to respond to changes in the operating conditions with fixed values of the empirical coefficients. The Yoon-Nelson model responds equally well under certain conditions. The Thomas model is recommended because of its ease of application.

\section{REFERENCES}

[1] Chemicals of Health Significance as described by World Health Organization Guidelines (WHO) for Drinkingwater Quality in third edition (2008) and fourth edition (2011)

[2] Z. Aksu, and F. Gonen "Biosorption of phenol by immobilized activated sludge in a continuous packed bed: Prediction of breakthrough curves," Process biochemistry, 39(5):599-613, 2004.

[3] H. Thomas, "Heterogeneous ion exchange in a flowing system.," Journal of the American Chemical Society, vol. 66, no. 10, pp. 1664-1666, 1944.

[4] Y. Yoon and J. Nelson, "Application of a gas adsorption kinetics I. A theoretical model for respirator cartridge service life," The American Industrial Hygiene Association Journal, vol. 45, no. 8, p. 509-516, 1984.

[5] Z. Xu, J.-g. Cai and B.-c. Pan, "Mathematically modeling fixed-bed adsorption in aqueous systems," Journal of Zhejiang University Science A., vol. 14, no. 3, pp. 155-176, 2013.

[6] A. Kardam, K. Raj, J. Arora and S. Srivastava, "Artificial neural network modeling for biosorption of $\mathrm{Pb}$ (II) ions on nanocellulose fibers," Bionanoscience, vol. 2, no. 3, pp. 153-160, 2012.

[7] A. Kiraz, O. Canpolat, E. Erkan and C. Ozer, "Artificial neural networks modeling for the prediction of $\mathrm{Pb}$ (II) adsorption," International Journal of Environmental Science and Technology, pp. 1-8, 2018.

[8] M. Bhaumik, K. Setshedi, A. Maity, and M. S. Onyango, "Chromium(VI) removal from water using fixed bed column of polypyrrole/Fe3O4 nanocomposite," Separation and Purification Technology, vol. 110, pp. 11-19, 2013.

[9] Y. Long, D. Lei, J. Ni, Z. Ren, C. Chen, and H. Xu, "Packed bed column studies on lead(II) removal from industrial wastewater by modified Agaricus bisporus," Bioresource Technology, vol. 152, pp. 457-463, 2014.

[10] A. Abdolali et al., "Application of a breakthrough biosorbent for removing heavy metals from synthetic and real wastewaters in a lab-scale continuous fixed-bed column," Bioresource Technology, vol. 229, pp. 78-87, 2017.

[11] M. Shezi, P. Musonge and S.L. Kiambi. Prediction of the performance of a biocomposite adsorption column for the removal of heavy metals from waste water. $3 r d$ International Conference on Composites, Biocomposites \& Nanocomposites, Port Elizabeth, South Africa. Vol. 3, pp. 451-480, 2018. 